\title{
A review of methods of intraoperative margin assessment in breast conserving surgery
}

\author{
Tomasz Sachańbiński', Barbara Radecka2,3 \\ 'Oncological Surgery Department with a Sub-department of Breast Diseases, Tadeusz Koszarowski Oncology Centre in Opole, Opole, Poland \\ 2Institute of Medical Sciences, Faculty of Medicine, University of Opole, Opole, Poland \\ ${ }^{3}$ Clinical Oncology Department with an Outpatient Unit, Tadeusz Koszarowski Oncology Centre in Opole, Opole, Poland
}

Breast conserving therapy is the primary treatment modality in early-stage breast cancer patients. Despite the development of methods for the intraoperative assessment of tumor margins, 20-30\% of patients still require re-resection due to postoperative tumor infiltration at the surgery margins. In recent years, many methods have been developed to reduce the number of re-resections due to margin infiltration. Here we review the current methods together with several more techniques under investigation.

Key words: breast conserving surgery, surgical margin, re-resection

\section{Introduction}

Breast conserving surgery (BCS) is the standard of care in patients with early-stage breast cancer (BC) [1]. In stage I and II, BCS is at least as effective as a mastectomy [2]. It includes resection of the primary breast tumor as well as diagnostic and therapeutic axillary procedures. Then the remaining mammary gland is irradiated. Most patients receive additional systemic (adjuvant) therapies depending on the pathological stage of the cancer and the biological subtype. One of the conditions for effective breast conserving therapy is obtaining clean margins, e.g. a site free of cancer cells, after surgical tumor resection [3]. The current definition of free surgical margins for invasive cancer is the absence of tumor cells in the surgical incision line (no ink on tumor) $[4,5]$. In ductal carcinoma in situ (DCIS), it is recommended to maintain a margin of not less than $2 \mathrm{~mm}$ from the surgical incision line [5].

Due to increasingly common screening tests and progress in imaging diagnostics, more and more breast cancers are detected during the preclinical phase. The early stage at diagnosis enables the widespread use of breast conserving therapy. Progress in adjuvant treatment - both systemic and radiotherapy - has significantly reduced the risk of local recurrence after BCS. Currently, the ten-year recurrence risk ranges between 4 and $7 \%$ [6]. In patients without tumor-free margins, the local recurrence risk increases two- to three-fold; therefore radical breast tumor resection is the main goal of conserving therapy $[4,7]$.

The intraoperative assessment of surgical margins remains a challenge for conserving therapy. Despite significant progress in this area, in $20-30 \%$ of cases the final histopathological examination still indicates the presence of cancer cells in the surgical incision line $[3,7]$. This results in reoperation - a local scar excision or mastectomy, which in turn extends the treatment duration, adversely affect the aesthetic effect, increasing the patient's stress and anxiety levels, and exacerbating the total treatment costs. Reoperation rates are higher for DCIS and breast invasive ductal carcinoma coexisting with ductal carcinoma in situ (IDC-DCIS), accounting for 46\% and 45\%, respectively $[8,9]$. Therefore, the use of sufficiently sensitive

\section{How to cite:}

Sachańbiński T, Radecka B. A review of methods of intraoperative margin assessment in breast conserving surgery. NOWOTWORY J Oncol 2021; 71: 225-231.

This article is available in open access under Creative Common Attribution-Non-Commercial-No Derivatives 4.0 International (CC BY-NC-ND 4.0) license, allowing to download articles and share them with others as long as they credit the authors and the publisher, but without permission to change them in any way or use them commercially. 
and specific methods of intraoperative assessment of resection margins is very important. None of the methods currently used are ideal, and research is ongoing to evaluate the different approaches. In the following sections we will present the available methods that increase the effectiveness of conserving therapy by reducing the rate of microscopic irradicality resulting in the need for reoperation.

\section{Surgical methods}

\section{Intraoperative gross clinical evaluation of the lumpectomy specimen}

This technique consists of an intraoperative clinical evaluation of the removed specimen and the resection bed to establish possible indications for extended resection. During the operation, the surgeon palpates the resected part of the breast and assesses the margins macroscopically. The surgeon assesses the tissue of the tumor bed and feels around for any suspicious lumps. The advantages of this procedure include its simplicity and relatively short duration; however, the sensitivity and specificity is low (<70\%), which significantly limits its usefulness in reducing the need for reoperation $[3,10]$.

\section{Routine resection of cavity shave margins (CSM)}

During the operation, the surgeon, after tumor resection, collects four, and if the preparation does not reach the skin and pectoral fascia, even six additional samples corresponding to the upper, lateral, medial and lower margins, and possibly the anterior (on the skin side) and the posterior (on the pectoral fascia side) [11]. Each of these tissue samples should be about $1 \mathrm{~cm}$ thick. Two meta-analyzes, comparing wide excision alone versus tumor excision with CSM, showed that routine use of the CSM significantly reduced the reoperation rate for margins infiltrations from $32 \%$ to $16 \%$ and from $31 \%$ to $12 \%$, respectively $[12,13]$. The size of the total part of breast removed in the CSM group is greater than in the group without CSM; however, according to the cited meta-analyzes, this does not affect the postoperative aesthetic effect $[12,13]$. On the contrary, there are single analyzes available that negate the beneficial effect of routinely used CSM in reducing reoperation rates [14].

\section{Microscopic method}

\section{Frozen section analysis (FSA)}

After processing, freezing and staining, the removed specimen is subjected to an intraoperative histopathological evaluation. This method requires transport of preparation to the histopathological laboratory and its preparation while the patient remains under anesthesia. This increases surgery duration by an average of 15-30 minutes [15, 16]. Ad hoc margin assessment does not completely eliminate the reoperations due to non-clean margins, although it can significantly reduce their rates even from 35\% to 10\% [15-17].
The sensitivity of this method ranges from $65 \%$ to $83 \%$ and the specificity exceeds $90 \%[15,16]$. Sensitivity decreases in DCIS, as well as when surgery is preceded by systemic treatment [17]. In some cases, tissue freezing may cause its damage and artifacts that hinder or prevent post-operative histopathological margin assessment.

\section{Ad hoc macroscopic margin assessment (MMA)}

In this method, the margin of the specimen removed is assessed macroscopically and intraoperatively by a pathologist, after marking the edges with ink. If any of the margins is smaller than $10 \mathrm{~mm}$, then it is simultaneously excised as an additional, extended margin. This procedure allows a reduction in the re-excision rate compared to surgery alone, from 34\% to 26\% [7].

\section{Touch imprint cytology/preparation}

This can be an alternative to the intraoperative margin assessment using FSA. This method is based on the increased ability of cancer cells to adhere to glass surfaces as opposed to fat cells [15]. During surgery, each margin of the removed specimen is pressed against a glass plate. The obtained cytological preparations are assessed by a pathologist. The advantage of this method compared to FSA is no consumption of tissue material and shorter evaluation time [15]. Additionally, the assessed impression captures the entire surface of the specimen (the entire margin), and not only selected areas $[15,18]$. The sensitivity and specificity of this method is comparable to FSA and account for up to $72 \%$ and $97 \%$, respectively [15]. However, cauterization (thermal damage) or drying of the margins can lead to false results in the cytological evaluation. For this reason, it is necessary to cooperate with a pathologist who has extensive experience in cytological assessment. It is worth noting that there are attempts to automate this assessment method [18].

\section{Radiological methods}

\section{Two-dimensional 2D mammography specimen}

After resection of part of the breast, an X-ray of the removed preparation is made. It allows to determine whether the target lesion has been removed and to assess the width of the radiological resection margins. Two images should be taken in perpendicular planes. This procedure is considered the gold standard in most cancer centers, and is also in line with the Polish Society of Oncological Surgery recommendations [19].

The advantages of this method include the relatively low complexity, and the availability and existing experience of radiologists. Thanks to standard mammography performed as part of preoperative diagnosis, it is possible to compare the images of the removed preparation with the preoperative ones. Thanks to the appropriate mammographic chambers, the intraoperative mammographic evaluation of removed tissue can also be performed directly in the operating room. 
This not only significantly reduces the rate of reoperations due to infiltrated margins, but also shortens the total procedure duration [20]. There is some criticism of specimen mammography usefulness as an ineffective method of margins assessment, while emphasizing its high value in confirming the removal of the target lesion $[21,22]$. The method allows for a reduction in the volume of the resected breast in the case of palpable lesions, which results in a better aesthetic effect [20]. It should be added that the accuracy of the mammographic margin assessment is significantly lower in the case of pre-invasive and lobular carcinomas [23].

\section{Digital breast tomosynthesis (DBT)}

DBT consists of taking a series of digital $X$-ray images of the preparation at different angles; from these photos a three-dimensional (3D) image is reconstructed (synthesized). Tomosynthesis improves assessment sensitivity by about $8 \%$ compared to conventional 2D imaging [24]. Assessment with this method is quick and requires little contribution of the support staff. The images obtained can be assessed in the operating room by the operating surgeon or sent for radiological evaluation. Using this imaging method, it is possible to verify the positive resection margins with a sensitivity of $77 \%$ and a specificity of 98\% [25]. In traditional mammography, the spatial image of the removed specimen is compressed into one flat image, which can result in a misassessment of the margins. Tomosynthesis enables evaluation of the entire resected specimen in $1 \mathrm{~mm}$ slices, which significantly reduces the risk of error $[24,26]$.

\section{Ultrasound of the removed part of breast}

An intraoperative ultrasound examination enables the localization and precise resection of palpable and nonpalpable breast masses. In the case of palpable lesions, an ultrasound allows better margin control compared to removal only under palpation, reducing the re-resection rate from $17 \%$ to $6 \%$ [27]. The volume of the removed preparation is also smaller, which may translate into better aesthetic effects [28]. In the case of nonpalpable lesions, the use of an intraoperative ultrasound with a high-frequency linear probe in combination with gross clinical evaluation in 223 patients allowed to obtain a precise lesion visualization in $99.6 \%$ of cases and to reduce the need for reoperation due to infiltrated margins to levels as low as $4 \%$ [28].

The challenges in using this method include invisible or poorly visible lesions on the ultrasonography (microcalcifications, small lesions in adipose tissue), as well as difficulties in visualizing pre-invasive cancer, or pre-invasive components around invasive cancer. In contrast, the assessment of lesions in breast glandular tissue may be better than using X-ray methods [29]. However, this requires the surgeon to be skilled in using ultrasound and the availability of high-class ultrasound machines in the operating theater.

\section{Micro CT}

The principle of operation is the same as in the case of conventional computed tomography, however, higher resolution is necessary. CT enables a spatial analysis of the removed specimen to be performed in order to assess resection margins, which eliminates the limitations of conventional 2D mammography. The studies conducted so far in a small group of patients show the possibility of reducing the need for reoperation from $31 \%$ to $14 \%$, however, they do not allow for an unequivocal assessment of the usefulness of this method in reducing the positive margins after conserving surgeries [30]. Furthermore, despite the higher resolution and high contrast between soft tissues, it is still difficult to distinguish between fibroglandular breast tissue and a tumor, which results in a low sensitivity of $56-60 \%[30,31]$.

\section{Magnetic resonance imaging (MRI)}

The advantage of MRI in the intraoperative assessment of a resected breast is the high possibility of differentiating soft tissues on the obtained images. The sensitivity of the cancer extent assessment in the resected specimen may reach up to $93 \%$ [32]. Due to the high spatial resolution, attempts are made to assess the lesions by a pathologist based on magnetic resonance images, which would eliminate the need to process and fix histopathological preparations. So far, the accuracy of this assessment is unsatisfactory (distinguishing a malignant from a benign lesion in 57\% of cases) [33]. Until recently, the time needed to obtain images, the need for pre-operative contrast administration and the size of the entire system were a serious limitation in the intraoperative use of this method. Lately, mobile MRI scanners have become available that do not require additional covers and enable developing satisfactory images without enhancing contrast. In a study involving 22 patients, a sensitivity of $91 \%$ and a specificity of $93 \%$ were achieved in distinguishing malignant from healthy tissues in the resected breast [32]

\section{Electromagnetic methods}

\section{Radiofrequency spectroscopy}

Radio waves emitted by the probe are absorbed, scattered and reflected differently by healthy and cancerous tissues. This is due to the lower electric potential of the tumor cell membrane compared to a normal cell, less mutual adhesion of tumor cells, greater vascularization of tumor tissues and the different morphology of the tumor cell nucleus. Due to these phenomena, the device emitting radiofrequency waves can distinguish between neoplastic and normal tissues. The transducer should be placed on the surface of the removed specimen. A positive reading indicates the presence of cancer cells to a depth of $1 \mathrm{~mm}$ from the edge of the specimen and obliges the surgeon to extent resection margin [34]. It is recommended to use the device in conjunction with standard techniques for imaging 
the removed tissue (mammography). Device sensitivity in the studies was estimated at $75-76 \%$ with a specificity of $46 \%$. The researchers emphasize that the device is not an ideal solution to the margins issue in BSC, but it is a considerable help, significantly reducing reoperation rates [35].

\section{Bioimpedance spectroscopy}

In a clinical setting, mobile, handheld devices are used; their principle of operation in margin assessment is based on the spectroscopic analysis of tissue impedance (the phenomenon of different dielectric properties of normal and neoplastic tissues is used). Due to different cell morphology, increased vascularization and mutual adherence of cells, neoplastic tissue has a lower impedance as well as higher conductivity and electrical permeability compared to healthy tissues. The technique is fast (the turnaround time is about 5 minutes) and does not require tissue damage (e.g. cutting and fixing). Limitations include the possibility of false results in inflammatory tissues, which bioimpedance may be similar to neoplastic tissues. In the analysis performed by Dixon et al., the need for reoperation due to infiltrated margins was reduced from $37 \%$ to $17 \%$, and after gaining more experience in using the device, even up to $9 \%$ of patients undergoing surgery compared to intraoperative margin assessment using a 2D radiograph [36]. One of the advantages of this device is its usefulness in assessing resection margins for both invasive and DCIS cancer and other atypical proliferative lesions [36].

It should be mentioned that a device operating on a similar principle was developed in 2017 in Wroclaw by M. Rząca et al. and is currently under study [37].

\section{Optical methods}

\section{Optical coherence tomography (OCT)}

This method uses infrared radiation and the phenomenon that cancer cells scatter waves differently. Cancer cells, due to the larger nucleus, higher cytosol density, and lower nuclear to cytoplasmic ratio, have greater capacity to scatter and reflect of electromagnetic waves compared to normal cells. The emitted and reflected radiation is captured by the detector and based on this the image is formed [38]. Since infrared permeability into the tissues reaches about $2 \mathrm{~mm}$, this method is very promising in the margin assessment of the resected breast. In the first studies comparing this method with postoperative histopathological assessment, the sensitivity and specificity of optical tomography was $91.7 \%$ and $92.1 \%$, respectively [39]. However, in subsequent clinical trials, much lower sensitivity and specificity was obtained, e.g. 55-65\% and 68-70\%, respectively [40].

\section{Photoacoustic tomography}

The method, currently being evaluated in preclinical studies, consists of treating the examined tissue with laser pulses.
The laser energy is partially reflected and radiated in the form of ultrasound waves detected by a suitable detector. The laser pulses penetrate into the tissue up to $3 \mathrm{~mm}$ deep. The difference in ultrasound wave frequency depends on the hemoglobin level and fat content in the tissues. So far, attempts to use this method concern only very small tissue surfaces and it performs well in fatty fragments, and much worse in glandular tissue [41].

\section{Fluorescence imaging}

There have been some attempts to use fluorescence for imaging and assessment of resection margins. These methods require dye administration (e.g., methylene blue or indocyanine green) prior to surgery. Thanks to the faster "washing out" of the dye from healthy cells and its longer retention in cancer cells, it is possible to assess (in infrared) whether there is dye accumulation in the resection margin [42]. Attempts are also being made to combine a dye (fluorophore) with a targeted antibody, such as an antibody binding to a vascular endothelial growth factor (VEGF), to increase the dye concentration in the tumor [43]. The limitation of this method, which is still under investigation, is the need to administer the substance before surgery and the fact that the currently used fluorophores are not selectively retained in breast tissues.

\section{Microscopy with ultraviolet surface excitation (MUSE)}

This method, currently being evaluated in preclinical studies, is based on stimulation of fluorophores by ultraviolet radiation falling on the surface. Ultraviolet radiation does not penetrate deeply and therefore has limited utility for assessing deeper layers of tissues. Assessing resection margins in DCIS can be problematic, but in the case of margins in invasive cancer, it is sufficient, according to the accepted consensus no ink on the tumor. MUSE seems to be a promising technique. An additional advantage of this method is that it does not damage tissues [44].

\section{Hybrid methods}

The combination of different methods of assessing the resected breast would make it possible to use the advantages of each of them, while partially compensating for their disadvantages. For example, radiological methods are very accurate when it comes to confirming complete resection, while spectroscopic or optical methods assess the surface of the resected breast with high accuracy, i.e. an infiltration-free resection margin. An example of such a hybrid system is mammography of a resected breast combined with a spectroscopy using electromagnetic waves. Mammography confirms the removal of a neoplastic lesion with high accuracy, while a spectroscopy assesses whether the margins of a resected specimen are free of cancer cells. The combination of these two assessments reduces the need for reoperation by up to $50 \%[45,46]$. Another hybrid approach is a device combining 
photoacoustic tomography with ultrasonography. The study on a small group of patients showed very high (100\%) sensitivity and high specificity in margin assessment [45].

\section{Other methods}

\section{Intelligent knife}

This technique analyzes the smoke produced by the electrocoagulation used to resect the specimen. Cell damage during the use of surgical diathermy results in the evaporation of their contents and transformation into an aerosol state. Using smoke spectrometric analysis and having established smoke models when cutting normal tissue and neoplastic tissue, it is possible to assess whether the cut is performed within normal or neoplastic tissues. Preliminary studies show a sensitivity of $77 \%$ with a very low number of false positive results $[46,47]$

\section{Nuclear medicine}

The use of positron emission tomography (PET) to assess the margins of a resected breast in clinical practice is currently not possible, taking into account the availability and complexity of the apparatus. However, there have been attempts involving preoperative administration of 18-fluorodeoxyglucose for the intraoperative evaluation of sentinel node and the margins of the resected breast. The unique evaluation which was carried out in two patients showed the high sensitivity and specificity of this method, however, the small number of patients makes it impossible to draw definitive conclusions regarding the effectiveness in resection margin assessment [48].

\section{Conclusions}

Numerous techniques have been developed for the intraoperative assessment of resection margins, which can significantly reduce reoperation rates. Some of these methods, however, are time and labor-intensive as well as expensive and with difficult access, which prevents their use in daily clinical practice in most centers. At the same time, intraoperative margin assessment according to the standard of care is necessary in every center specializing in the management of $B C$ patients. The procedure still in force in Poland is the intraoperative mammographic evaluation of the resected part of the breast. Intraoperative ultrasound, tomosynthesis and microtomography are increasingly used. Some centers use ad hoc histopathological margin assessment, although this is associated with a significant extension of the total procedure duration. Spectroscopic techniques are noteworthy due to their short evaluation time and simple operation. In combination with standard imaging techniques - mammography, ultrasound - they can be a significant help in margin assessment in the future. Other methods, as promising as they are, are not yet developed enough to be used as a standard of care.
However, it is important that each breast cancer center monitors the rate of re-resections due to margin infiltration, ensuring every effort is made to reduce it. A standard of care in the intraoperative evaluation of the preparation should be developed based on the Polish Society of Oncological Surgery recommendations and, depending on the availability of additional methods, should be systematically improved. The key to success is an accurate preoperative diagnosis, precise marking of malignant lesion and a refined method of intraoperative margin assessment [49].

\section{Conflict of interest: none declared}

\section{Tomasz Sachańbiński}

Tadeusz Koszarowski Oncology Centre in Opole

Oncological Surgery Department with a Sub-department of Breast

Diseases

ul. Katowicka 66 a

45-060 Opole, Poland

e-mail:saszkin73@gmail.com

Received: 24 Jan 2021

Accepted: 18 Mar 2021

\section{References}

1. Jeziorski A, Rutkowski P, Wysocki W. Chirurgia onkologiczna t. 2. PZWL, Warszawa 2018: 820-821.

2. Veronesi U, Cascinelli N, Mariani L, et al. Twenty-year follow-up of a randomized study comparing breast-conserving surgery with radical mastectomy for early breast cancer. N Engl J Med. 2002; 347(16): 12271232, doi: 10.1056/NEJMoa020989, indexed in Pubmed: 12393819.

3. Houssami N, Macaskill P, Marinovich ML, et al. The association of surgical margins and local recurrence in women with early-stage invasive breast cancer treated with breast-conserving therapy: a meta-analysis. Ann Surg Oncol. 2014; 21(3): 717-730, doi: 10.1245/s10434-014-3480-5, indexed in Pubmed: 24473640.

4. Moran MS, SchnittSJ, Giuliano AE, et al. Society of Surgical Oncology-American Society for Radiation Oncology consensus guideline on margins for breast-conserving surgery with whole-breast irradiation in stages I and II invasive breast cancer. Int J Radiat Oncol Biol Phys. 2014; 88(3): 553-564, doi: 10.1016/j.jijobp.2013.11.012, indexed in Pubmed: 24521674.

5. Morrow M, Van Zee KJ, Solin LJ, et al. Society of Surgical Oncology-American Society for Radiation Oncology-American Society of Clinical Oncology Consensus Guideline on Margins for Breast-Conserving Surgery with Whole-Breast Irradiation in Ductal Carcinoma In Situ. Ann Surg Oncol. 2016; 23(12):3801-3810, doi: 10.1245/s10434-016-5449-Z, indexed in Pubmed: 27527714.

6. Morrow M, Van Zee KJ, Solin LJ, et al. Society of Surgical Oncology, American Society for Radiation Oncology. Surgical margins in lumpectomy for breast cancer--bigger is not better. N Engl J Med. 2012; 367(1): 79-82, doi: 10.1056/NEJMsb1202521, indexed in Pubmed: 22762325.

7. Bolger JC, Solon JG, Khan SA, et al. A comparison of intra-operative margin management techniques in breast-conserving surgery: a standardised approach reduces the likelihood of residual disease without increasing operative time. Breast Cancer. 2015; 22(3): 262-268, doi: 10.1007/s12282-013-0473-3, indexed in Pubmed: 23649303.

8. Dillon MF, Mc Dermott EW, O'Doherty A, et al. Factors affecting successful breast conservation for ductal carcinoma in situ. Ann Surg Oncol. 2007; 14(5): 1618-1628, doi: 10.1245/s10434-006-9246-y, indexed in Pubmed: 17443388.

9. Dunne C, Burke JP, Morrow M, et al. Effect of margin status on local recurrence after breast conservation and radiation therapy for ductal carcinoma in situ. J Clin Oncol. 2009; 27(10): 1615-1620, doi: 10.1200/ JCO.2008.17.5182, indexed in Pubmed: 19255332.

10. Balch G, Mithani S, Simpson J, et al. Accuracy of Intraoperative Gross Examination of Surgical Margin Status in Women Undergoing Partial Mastectomy for Breast Malignancy. The American Surgeon. 2005; 71(1): 22-28, doi: $10.1177 / 000313480507100104$. 
11. Chagpar AB, Killelea BK, Tsangaris TN, et al. A Randomized, Controlled Trial of Cavity Shave Margins in Breast Cancer. N Engl J Med. 2015; 373(6): 503-510, doi: 10.1056/NEJMoa1504473, indexed in Pubmed: 26028131.

12. Wang $\mathrm{Ke}$, Ren $\mathrm{Yu}, \mathrm{He}$ J. Cavity Shaving plus Lumpectomy versus Lumpectomy Alone for Patients with Breast Cancer Undergoing Breast-Conserving Surgery: A Systematic Review and Meta-Analysis. PLoS One. 2017; 12(1): e0168705, doi: 10.1371/journal.pone.0168705, indexed in Pubmed: 28046058.

13. CLEMENT Z. Should cavity shave margins be performed as a routine in breast conserving surgery? A review of randomised controlled trials. Int J Surg Med. 2017; 3(2): 1, doi: 10.5455/ijsm.cavity-shave-margin-breast-conserving-surgery.

14. Tang R, Coopey SB, Buckley JM, et al. Lumpectomy cavity shaved margins do not impact re-excision rates in breast cancer patients. Ann Surg Oncol. 2011; 18(11): 3036-3040, doi: 10.1245/s10434-011-1909-7, indexed in Pubmed: 21947583.

15. Esbona K, Li Z, Wilke LG. Intraoperative imprint cytology and frozen section pathology for margin assessment in breast conservation surgery: a systematic review. Ann Surg Oncol. 2012; 19(10): 3236-3245, doi: 10.1245/s10434-012-2492-2, indexed in Pubmed: 22847119.

16. Nowikiewicz T, Śrutek E, Głowacka-Mrotek I, et al. Clinical outcomes of an intraoperative surgical margin assessment using the fresh frozen section method in patients with invasive breast cancer undergoing breast-conserving surgery - a single center analysis. Sci Rep. 2019; 9(1): 13441, doi: 10.1038/s41598-019-49951-y, indexed in Pubmed: 31530867.

17. Riedl O, Fitzal F, Mader N, et al. Intraoperative frozen section analysis for breast-conserving therapy in 1016 patients with breast cancer. Eur J Surg Oncol. 2009; 35(3): 264-270, doi: 10.1016/j.ejso.2008.05.007, indexed in Pubmed: 18706785.

18. Martin DT, Sandoval S, Ta CN, et al. Quantitative automated image analysis system with automated debris filtering for the detection of breast carcinoma cells. Acta Cytol. 2011; 55(3): 271-280, doi: 10.1159/000324029, indexed in Pubmed: 21525740.

19. Nowecki ZJ, Jeziorski A. Chirurgiczne leczenie zmian nowotworowych piersi Konsensus Polskiego Towarzystwa Chirurgii Onkologicznej. Onkol W Prakt Klin - Eduk. 2017; 3(3): 93-153.

20. Layfield DM, May DJ, Cutress Rl, et al. The effect of introducing an in-theatre intra-operative specimen radiography (IOSR) system on the management of palpable breast cancer within a single unit. Breast. 2012; 21(4): 459-463, doi: 10.1016/j.breast.2011.10.010, indexed in Pubmed: 22119488

21. Bimston DN, Bebb GG, Wagman LD. Is specimen mammography beneficial? Arch Surg. 2000; 135(9): 1083-6; discussion 1086, doi: 10.1001/ archsurg.135.9.1083, indexed in Pubmed: 10982514.

22. Britton PD, Sonoda LI, Yamamoto AK, et al. Breast surgical specimen radiographs: how reliable are they? Eur J Radiol. 2011; 79(2): 245-249, doi: 10.1016/j.ejrad.2010.02.012, indexed in Pubmed: 20303687.

23. McCormick JT, Keleher AJ, Tikhomirov VB, et al. Analysis of the use of specimen mammography in breast conservation therapy. Am J Surg. 2004; 188(4): 433-436, doi: 10.1016/j.amjsurg.2004.06.030, indexed in Pubmed: 15474443

24. Schulz-Wendtland R, Dilbat G, Bani MR, et al. Use of Tomosynthesis in Intraoperative Digital Specimen Radiography - Is a Reduction of Breast Re-excision Rates Possible? Geburtshilfe Frauenheilkd. 2011; 71(12): 1080-1084, doi: 10.1055/s-0031-1280427, indexed in Pubmed: 25253902.

25. Amer HA, Schmitzberger F, Ingold-Heppner B, et al. Digital breast tomosynthesis versus full-field digital mammography-Which modality provides more accurate prediction of margin status in specimen radiography? Eur J Radiol. 2017; 93: 258-264, doi: 10.1016/j.ejrad.2017.05.041, indexed in Pubmed: 28668424.

26. Chand JT, Sharma MM, Dharmarajan JP, et al. Digital Breast Tomosynthesis as a Tool in Confirming Negative Surgical Margins in Non-palpable Breast Lesions. Indian J Surg Oncol. 2019; 10(4):624-628, doi: 10.1007/ s13193-019-00956-z, indexed in Pubmed: 31857754.

27. Karanlik H, Ozgur I, Sahin D, et al. Intraoperative ultrasound reduces the need for re-excision in breast-conserving surgery. World J Surg Oncol. 2015; 13: 321, doi: 10.1186/s12957-015-0731-2, indexed in Pubmed: 26596699.

28. Ramos M, Díaz JC, Ramos T, et al. Ultrasound-guided excision combined with intraoperative assessment of gross macroscopic margins decreases the rate of reoperations for non-palpable invasive breast cancer. Breast. 2013;22(4):520-524, doi: 10.1016/j.breast.2012.10.006, indexed in Pubmed: 23110817.
29. Mesurolle B, El-Khoury M, Hori D, et al. Sonography of postexcision specimens of nonpalpable breast lesions: value, limitations, and description of a method. AJR Am J Roentgenol. 2006; 186(4): 1014-1024, doi: 10.2214/AJR.05.0002, indexed in Pubmed: 16554572.

30. Qiu SQ, Dorrius MD, de Jongh SJ, et al. Micro-computed tomography (micro-CT) for intraoperative surgical margin assessment of breast cancer: $A$ feasibility study in breast conserving surgery. Eur J Surg Oncol. 2018;44(11): 1708-1713, doi:10.1016/j.ejso.2018.06.022, indexed in Pubmed:30005963.

31. McClatchy DM, Zuurbier RA, Wells WA, et al. Micro-computed tomography enables rapid surgical margin assessment during breast conserving surgery $(B C S)$ : correlation of whole BCS micro-CT readings to final histopathology. Breast Cancer Res Treat. 2018; 172(3): 587-595, doi: 10.1007/s10549-018-4951-3, indexed in Pubmed: 30225621.

32. Papa M, Allweis T, Karni T, et al. An intraoperative MRI system for margin assessment in breast conserving surgery: Initial results from a novel technique. J Surg Oncol. 2016; 114(1): 22-26, doi: 10.1002/jso.24246, indexed in Pubmed: 27080211.

33. Dashevsky BZ, D'Alfonso T, Sutton EJ, et al. The Potential of High Resolution Magnetic Resonance Microscopy in the Pathologic Analysis of Resected Breast and Lymph Tissue. Sci Rep. 2015; 5: 17435, doi: 10.1038/ srep17435, indexed in Pubmed: 26639673.

34. Thill M. MarginProbe: intraoperative margin assessment during breast conserving surgery by using radiofrequency spectroscopy. Expert Rev Med Devices. 2013; 10(3): 301-315, doi: 10.1586/erd.13.5, indexed in Pubmed: 23668703.

35. Schnabel F, Boolbol SK, Gittleman M, et al. A randomized prospective study of lumpectomy margin assessment with use of MarginProbe in patients with nonpalpable breast malignancies. Ann Surg Oncol. 2014; 21(5): 1589-1595, doi: 10.1245/s10434-014-3602-0, indexed in Pubmed: 24595800.

36. Dixon JM, Renshaw L, Young O, et al. Intra-operative assessment of excised breast tumour margins using ClearEdge imaging device. Eur J Surg Oncol. 2016; 42(12): 1834-1840, doi: 10.1016/j.ejso.2016.07.141, indexed in Pubmed: 27591938.

37. Rząca M, Orzechowski K, Wolny A, et al. Chirurgia raka gruczołu piersiowego wspomagana technikami dielektrycznymi. Biuletyn PTO NOWOTWORY. 2017; 2(2): 140-147.

38. Nguyen FT, Zysk AM, Chaney EJ, et al. Intraoperative evaluation of breast tumor margins with optical coherence tomography. Cancer Res. 2009; 69(22): 8790-8796, doi: 10.1158/0008-5472.CAN-08-4340, indexed in Pubmed: 19910294.

39. Erickson-Bhatt SJ, Nolan RM, Shemonski ND, et al. Real-time Imaging of the Resection Bed Using a Handheld Probe to Reduce Incidence of Microscopic Positive Margins in Cancer Surgery. Cancer Res. 2015; 75(18): 3706-3712, doi: 10.1158/0008-5472.CAN-15-0464, indexed in Pubmed: 26374464.

40. Zysk AM, Chen K, Gabrielson E, et al. Intraoperative Assessment of Final Margins with a Handheld Optical Imaging Probe During Breast-Conserving Surgery May Reduce the Reoperation Rate: Results of a Multicenter Study. Ann Surg Oncol. 2015; 22(10): 3356-3362, doi: 10.1245/s10434-015-4665-2, indexed in Pubmed: 26202553.

41. Nyayapathi N, Xia J. Photoacoustic imaging of breast cancer: a mini review of system design and image features. J Biomed Opt. 2019;24(12): 1-13, doi: 10.1117/1.JBO.24.12.121911, indexed in Pubmed: 31677256.

42. Tummers QR, VerbeekFPR, Schaafsma BE, et al. Real-time intraoperative detection of breast cancer using near-infrared fluorescence imaging and Methylene Blue. Eur J Surg Oncol. 2014; 40(7): 850-858, doi: 10.1016/j.ejso.2014.02.225, indexed in Pubmed: 24862545.

43. Lamberts LE, Koch M, de Jong JS, et al. Tumor-Specific Uptake of Fluorescent Bevacizumab-IRDye800CW Microdosing in Patients with Primary Breast Cancer: A Phase I Feasibility Study. Clin Cancer Res. 2017; 23(11): 2730-2741, doi: 10.1158/1078-0432.CCR-16-0437, indexed in Pubmed: 28119364.

44. Xie W, Chen Ye, Wang Yu, et al. Microscopy with ultraviolet surface excitation for wide-area pathology of breast surgical margins. J Biomed Opt. 2019; 24(2): 1-11, doi: 10.1117/1.JBO.24.2.026501, indexed in Pubmed: 30737911.

45. Goh Y, Balasundaram G, Moothanchery M, et al. Ultrasound Guided Optoacoustic Tomography in Assessment of Tumor Margins for Lumpectomies. Transl Oncol. 2020; 13(2): 254-261, doi: 10.1016/j. tranon.2019.11.005, indexed in Pubmed: 31869750.

46. St John ER, Balog J, McKenzie JS, et al. Rapid evaporative ionisation mass spectrometry of electrosurgical vapours for the identification of breast pathology: towards an intelligent knife for breast cancer surgery. Breast Cancer Res. 2017; 19(1): 59, doi: 10.1186/s13058-017-0845-2, indexed in Pubmed: 28535818. 
47. John ESt, Rossi M, Balog J, et al. Real time intraoperative classification of breast tissue with the intelligent knife. Eur J Surg Oncol. 2016; 42(5): S25, doi: 10.1016/j.ejso.2016.02.102.

48. Hall NC, Povoski SP, Murrey DA, et al. Combined approach of perioperative 18F-FDG PET/CT imaging and intraoperative 18F-FDG handheld gamma probe detection for tumor localization and verification of complete tumor resection in breast cancer. World J Surg Oncol. 2007; 5: 143, doi: 10.1186/1477-7819-5-143, indexed in Pubmed: 18154677.

49. Dixon JM, Newlands C, Dodds C, et al. Association between underestimation of tumour size by imaging and incomplete excision in breast-conserving surgery for breast cancer. Br J Surg. 2016; 103(7): 830-838, doi: 10.1002/bjs.10126, indexed in Pubmed: 27171027. 